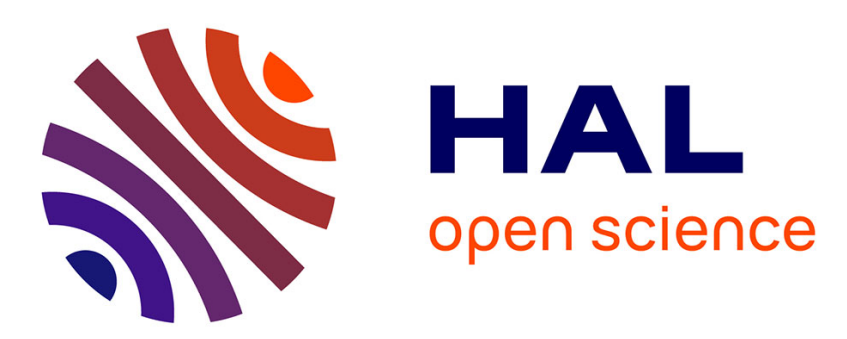

\title{
A renewed understanding of shell-shape diversity among marine gastropod species: invariance and covariance between geometrical parameters in conispirally coiled shells. \\ Jean Béguinot
}

\section{To cite this version:}

Jean Béguinot. A renewed understanding of shell-shape diversity among marine gastropod species: invariance and covariance between geometrical parameters in conispirally coiled shells.. Annual Research \& Review in Biology, 2017, 13 (2), pp.1-17. 10.9734/ARRB/2017/33935 . hal-01625531

\section{HAL Id: hal-01625531 \\ https://hal.science/hal-01625531}

Submitted on 27 Oct 2017

HAL is a multi-disciplinary open access archive for the deposit and dissemination of scientific research documents, whether they are published or not. The documents may come from teaching and research institutions in France or abroad, or from public or private research centers.
L'archive ouverte pluridisciplinaire HAL, est destinée au dépôt et à la diffusion de documents scientifiques de niveau recherche, publiés ou non, émanant des établissements d'enseignement et de recherche français ou étrangers, des laboratoires publics ou privés. 


\title{
A Renewed Understanding of Shell-shape Diversity among Marine Gastropod Species: Invariance and Covariance between Geometrical Parameters in Conispirally Coiled Shells
}

\author{
Jean Béguinot ${ }^{1^{*}}$ \\ ${ }^{1}$ Department of Biogéosciences, Université de Bourgogne, F 21000 Dijon, France.
}

Author's contribution

The sole author designed, analyzed and interpreted and prepared the manuscript.

Article Information

DOI: $10.9734 / A R R B / 2017 / 33935$

Editor(s):

(1) George Perry, Dean and Professor of Biology, University of Texas at San Antonio, USA.

Reviewers:

(1) R. Carlos Andres Satizabal, The University of Tokyo, Japan. (2) Claudio J. Bidau, Universidad Nacional De Rio Negro, Argentina. (3) Fabiane Borba Bergmann, Secretaria Municipal de Meio Ambiente, Rio Grande do Sul, Brazil. (4) Maria José Conceção, Federal University, Brazil. Complete Peer review History: http://www.sciencedomain.org/review-history/19369

Original Research Article

Received $4^{\text {th }}$ May 2017 Accepted $31^{\text {st }}$ May 2017 Published $6^{\text {th }}$ June 2017

\begin{abstract}
Approximately conispirally coiled shells make the bulk of shell structure among marine gastropod species, apart from those shells with strongly overlapping whorls (typical, in particular, of Cones, Cowries and the like). By selecting appropriately the set of geometrical parameters appropriate to describe the interspecific variations of shell-shape, an original pattern of covariances and independences was unveiled between these parameters, providing, in turn, a partly renewed understanding of the interspecific diversification of shell-shapes among conispirally coiled marine gastropods. This novel approach should be considered as complementary, rather than alternative, to the traditional and well established models by RAUP and others. Among the four selected descriptive parameters (the whorl expansion ratio, the degree of whorl compression, the number of whorls of fully blown shell and the shell apical angle), four strong covariances and two mutual independences are empirically documented and analysed theoretically. Two covariances (apical angle covarying positively with the whorl expansion ratio and negatively with the degree of whorl compression) are imposed by geometrical constraints exclusively; one covariance (negative
\end{abstract}

${ }^{*}$ Corresponding author: E-mail: jean-beguinot@orange.fr; 
between the number of whorls and the whorl expansion ratio) is likely attributable to purely biological causes, tentatively associated to either developmental or functional constraints; while the last covariance (negative between apical angle and number of whorls) involves both geometrical and biological determinisms.

Thus, the conispiral coiling mode, in marine gastropods, involves quite an intricate interplay of covariances among the parameters describing shell-shape. While limiting thereby the range of occupation of the potential morphospace, this pattern of covariances introduces enhanced shell shape complexity. Highlighting this underlying complexity may, in turn, contribute to a more thorough and fundamental understanding of the ontogenetic aspects involved in the profuse diversity of shell-shapes among marine gastropods.

Keywords: Apex; constraint; development; dependence; expansion; function; geometry; independence; mollusk; Raup; snail; whorl.

\section{INTRODUCTION}

Among the indefinitely diverse range of 'natural forms', the less complex or more regular ones may often be satisfactorily described in terms of relatively simple geometric models, involving a small number of geometrical parameters. Gastropods shells provide fair examples in this respect. Indeed, gastropods shells, especially marine gastropod shells, are quite remarkable in that the intricate interplay of only a few geometrical parameters makes it possible to generate an impressive diversity of shell shape variations flourishing from a common, simple basic design, fundamentally centered on the classical conispiral coiling model $[1,2]$. As pointed out by Vermeij [3], "The shells of mollusks derive much of their aesthetic appeal from the regularity of their form" and further: "Beneath the great diversity of forms, there is a surprising unity of molluscan design". These remarks invite to understand more about the ins and outs regarding the origin of such a diversity of shapes, yet stemming from so simple a common generic design. In a sentence that ideally fits d'Arcy Thompson's original conceptions [1], Vermeij adds: "Once we know the rules of growth and form, we can ask why certain shapes that are compatible with the rules are rarely or never encountered in nature". Among significant revealers of these rules (and also their suggestive exceptions) are the more or less strong interspecific correlations - positive or negative - that actually occur between appropriately selected geometrical parameters that describe the shell shape in conispirally coiled gastropods shells $[4,5]$. At first, some of these covariances may result from purely geometrical constraints. Yet, more interesting at a biological point of view are those covariances liable to the more or less strict invariance of still another parameter, invariance resulting from some biological constraint(s), as discussed later. Whatever the nature and origins of the constraints involved, these covariances cast new light upon the underlying process responsible for the patterns of shell-shape diversity among marine gastropod species. Rational explanations may thereby be provided to the resulting restrictions of the potential morphospace occupancy, as empirically recorded $[6,7]$.

In spite of the relative simplicity of the basic conispiral coiling model, different sets of geometrical parameters (see section Methods) may alternatively serve to account for the dramatic variability of shell-shape derived from this generic model. Yet, these different sets of descriptive parameters differ from one another in their ability to address appropriately and discover the causes - either geometrical, developmental or functional - that ultimately govern the interspecific variability of shellshapes. Opportunely choosing the more appropriate set of geometrical parameters to investigate shell-shape variability is thus of decisive concern, at first.

In this perspective, I propose hereafter to select an original set of four parameters accounting for the main geometrical traits of conispirally coiled shells. The selection of this particular combination of geometrical parameters proves empirically being particularly appropriate to uncover the geometrical and biological constraints which, ultimately, delineate the restricted pattern of occupancy of the corresponding morphospace. And thereby explain the pattern of shell-shape diversity among marine conispirally coiled gastropod species.

On this basis, I then report on the occurrence of four strong and unexpected covariances and two 
quasi-independences within the six pairwise combinations of these four parameters. I discuss the likely causes of each of the four unexpected covariances, considering the respective relevance of either geometrical, developmental or functional constraints. Keeping in mind that distinguishing between developmental and functional constraints often reveals far from obvious [8].

Finally, the specific case of those gastropod shells with strongly overlapping whorls, which clearly distinguishes from the conispiral model, is addressed comparatively.

\section{MATERIALS AND METHODS}

In marine gastropods, approximately conispirally coiled shells make the bulk of shell structures [3], apart from those shells with strongly overlapping whorls, typically exemplified by Cones, Cowries and the like (Olividae, Cystiscidae, Marginellidae, Triviidae, Cassidae, Strombidae and also Naticidae, Neritidae, ... ).

Since d'Arcy Thompson, three-parameters descriptions are widely used to account for the main geometrical traits of conispirally coiled gastropods shells. Thompson [1] considers (i) the spiral angle (directly related to the whorl expansion rate), (ii) the apex angle and (iii) the retardation angle, while Raup [2,9] classically makes use of (i) the whorl expansion rate, (ii) the translation and (iii) the distance from the axis to the generating curve.

Hereafter, I consider a partly different set of parameters. Four (instead of only three) parameters were selected considering their particular ability to highlight the role of different kinds of constraints, resulting in the interplay of strong covariances occurring between these parameters which, in turn, explain the recorded pattern of shell-shape diversity.

For this selection of four parameters, I borrow from the two preceding authors:

(i) the whorl expansion rate ' $\varepsilon$ ' (defined as the average relative increment in whorl section after any single additional turn) and from THOMPSON alone:

(ii) The apical angle, hereafter labelled ' $\alpha$ '. Note that in the comparatively rare occurrences of significant umbilicus opening angle, the latter is of course deducted from the apical angle to obtain the correct value of $\alpha$ ).

I add two other parameters to the two previous ones:

(iii) The number of whorls of fully blown shell, 'v', a too often overlooked parameter, usually neglected in spite of its obvious relevance in terms of shell shape. This stands not only for those species having determinate growth but also for the other species for which the number of whorls of fully blown shells, although less accurately controlled, makes sense however. Indeed, conchologists routinely distinguish between gastropod species having shells with more or less whorls at fully blown state; for example, conchologists admittedly recognize the compensation between the number of whorls of fully blown shells and the corresponding whorl expansion ratio among marine gastropod species.

(iv) The degree of whorl lateral compression ' $\varphi$ ', defined as the ratio between the whorl section height (measured parallel to the coiling axis) and the whorl section width (measured perpendicular to the coiling axis): the ratio $(a / b)$ in Fig. 1.

The occurrence of pairwise invariances / covariances among the four selected parameters $\varepsilon, \alpha, v, \varphi$, was investigated from measurements applied to a subset of marine gastropod species with approximately conospirally coiled shells, included in the catalogs of marine gastropods shells by Robin [10] and Hill [11]. In spite of the considerable volume of iconographic data made available in these catalogs, sufficiently accurate measurements were practically obtained for a selection of 51 species only (listed in Appendix 1).

Although limited in number, this subset of species fairly encompasses the ranges of taxonomic and shell-shape diversity among approximately conically coiled marine gastropods. The mode of selection of species, according to their level of iconographic quality allowing sufficiently accurate measurements, is not likely to create an artificial pattern of covariance between the parameters involved in the study.

In practice, the number of whorls $v$ was estimated to the nearest half revolution (or to the 


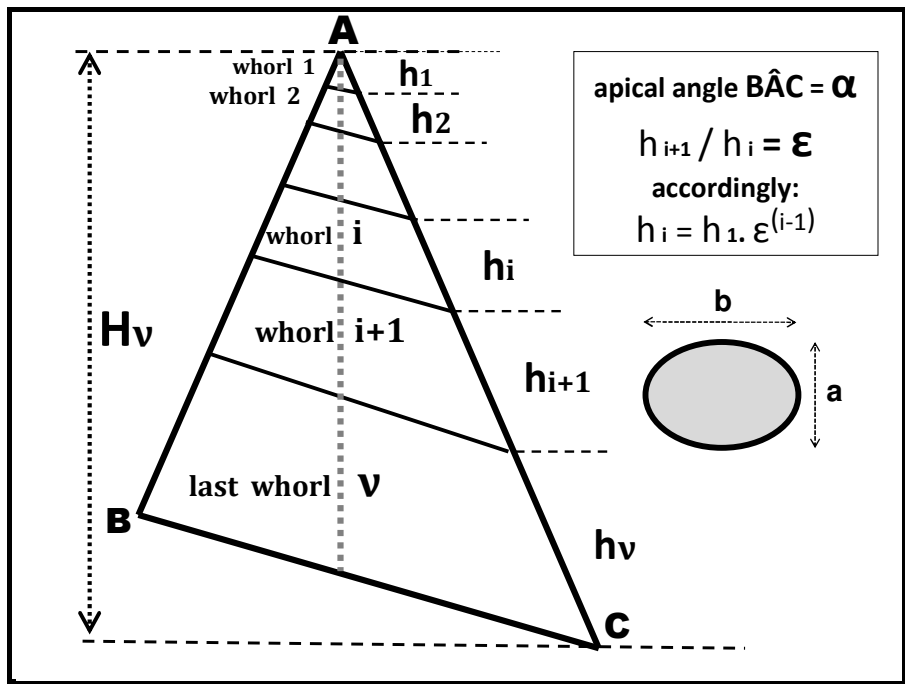

Fig. 1. Schematic representation of four main geometrical parameters for an ideally conispirally coiled shell: apical angle $\alpha$, whorl expansion ratio $\varepsilon$, number of whorls $v$ of fully blown shell. ' $H_{v}$ ' designs the height of fully blown shell, ' $h{ }_{i}$ ' the height of the $i^{\text {th }}$ whorl, ' $a$ ' and ' $b$ ' are the whorl section height and width respectively and $\varphi=a / b$

nearest revolution for $v>10$ ), the expansion rate $\varepsilon$ was estimated with a precision of $\pm 5 \%$ and the apical angle with a precision of \pm $2^{\circ}$.

The precision of measurements, although less than what would be obtained directly upon specimens, proves, a posteriori, being sufficient for testing the existence of significant covariances that may occur between these parameters.

\section{RESULTS}

Testing for either mutual independence or significant pairwise covariance between the four geometrical parameters selected in this study leads to examine successively the six following doublets: $\{\varepsilon-\varphi\} ;\{v-\varphi\} ;\{v-\varepsilon\} ;\{\alpha-\varepsilon\} ;\{\alpha-\varphi\} ;\{\alpha-v\}$; that are obtained by grouping, two by two, these four parameters.

The regression of $\varepsilon$ against $\varphi$ (Fig. 2) shows that the variations of the whorl expansion rate $\varepsilon$ do not explain more than $9 \%$ of the variations of the whorl compression index $\varphi$ (coefficient of determination $\left.r^{2}=0.086\right)$. Therefore, parameters $\varepsilon$ and $\varphi$ may be considered as fairly independent. Similarly, the regression of $v$ against $\varphi$ (Fig. 3) shows that the variations of the whorl compression index $\varphi$ explains only $6 \%$ of the variations of the number of whorls $v$ of fully blown shells (coefficient of determination $r^{2}=0.060$ ).
Therefore, $v$ and $\varphi$ may also be considered as fairly independent.

By contrast, the regression of $v$ against $\varepsilon$ (Fig. 4) highlights a strong and highly significant negative covariance between the number of whorls $v$ of fully blown shells and the whorl expansion rate $\varepsilon$ $(r=-0.84, p<0.0001)$.

The regression of a versus $\varepsilon$ (Fig. 5) shows a strong, highly significant positive covariance between the apical angle $\alpha$ and the whorl expansion rate $\varepsilon(r=-0.88, p<0.0001)$.

On the contrary, the regression of $\alpha$ versus $\varphi$ (Fig. 6) shows a strong, highly significant negative covariance between the apical angle $\alpha$ and the whorl compression index $\varphi(r=-0.68, p$ $<0.0001)$. At last, the regression of $\alpha$ versus $v$ (Fig. 7) shows a strong, highly significant negative covariance between the apical angle $\alpha$ and the number of whorls of fully blown shells $v$ $(r=-0.87, p<0.0001)$.

\section{DISCUSSION}

Among marine gastropods, conispiral coiling is the clearly dominant [3], while not exclusive pattern. Four geometrical parameters were selected to appropriately account for the main traits of shell-shape in conispirally coiled shells: the whorl expansion ratio ' $\varepsilon$ ', the degree of lateral whorl compression ' $\varphi$ ', the number of whorls of 
fully blown shell ' $v$ ' and the apical angle ' $\alpha$ ' (with deduction of the umbilicus opening angle if any).

Admittedly, some gastropods acceptably considered as conispirally coiled may, yet, match only approximately the strictly ideal conispiral coiling model. My objective, however, was to seek for and highlight at best, the most prominent general trends of shell architecture within the bulk of conispirally coiled shells, would it be at the expense of more or less diverging secondary features.

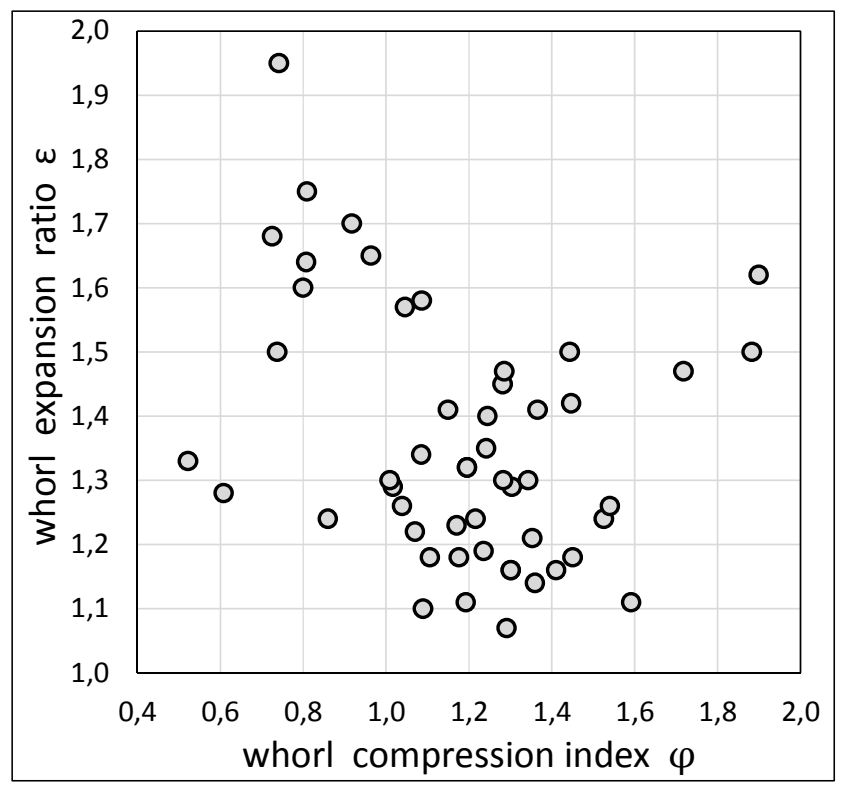

Fig. 2. The recorded distribution of the whorl expansion ratio $\varepsilon$ versus the whorl compression index $\varphi$ for a set of 51 species of marine gastropods. The coefficient of determination $r^{2}$ equals 0.086 and the contribution of each parameter to the variations of the other is less than $9 \%$

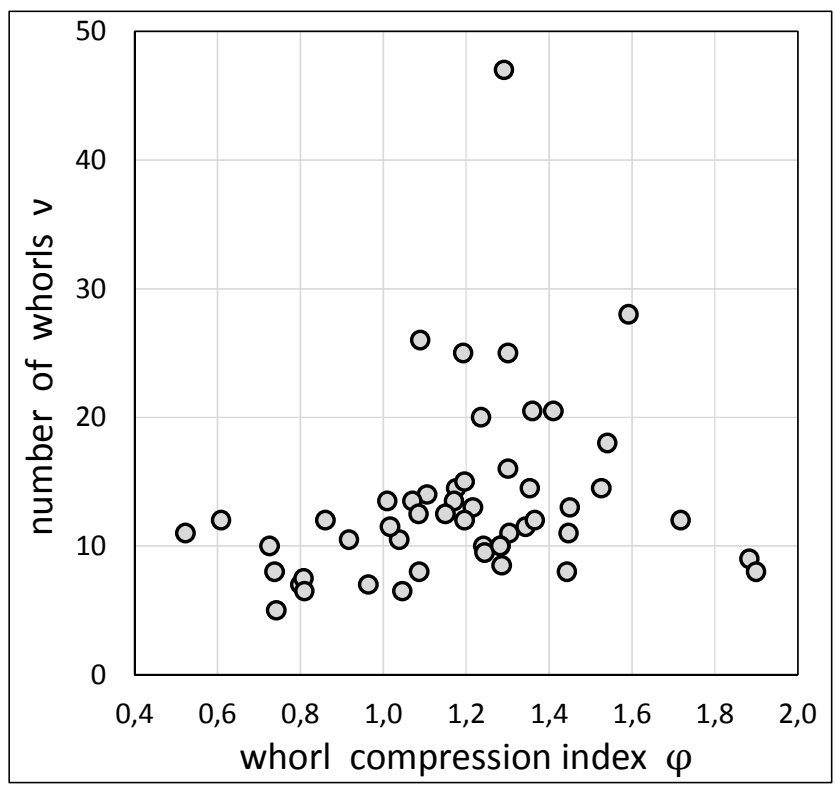

Fig. 3. The recorded distribution of the number of whorls $v$ versus the whorl compression index $\varphi$ for a set of 51 species of marine gastropods. The coefficient of determination $r^{2}$ equals 0.060 and the contribution of each parameter to the variations of the other is less than $6 \%$ 


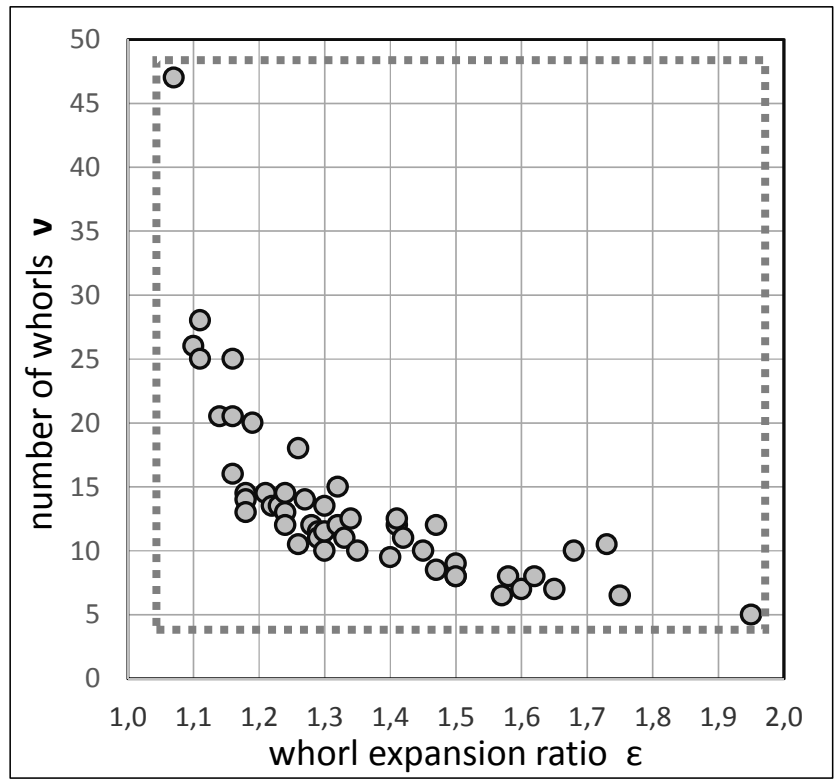

Fig. 4. The recorded distribution of the number of whorls $v$ of the fully grown spire versus the whorl expansion rate $\varepsilon$ for a set of 51 species of marine gastropods. The number of whorls $\mathbf{v}$ is strongly decreasing with growing values of their expansion rate $\varepsilon$ (power regression $r=-$

$0.84, p<0.0001)$. Due to this strong negative covariance, less than $20 \%$ of the potential morphospace $\{\varepsilon, v\}$ (dotted rectangle: $[\varepsilon=1.05-1.95] \times[v=5-48]$ ) is actually occupied

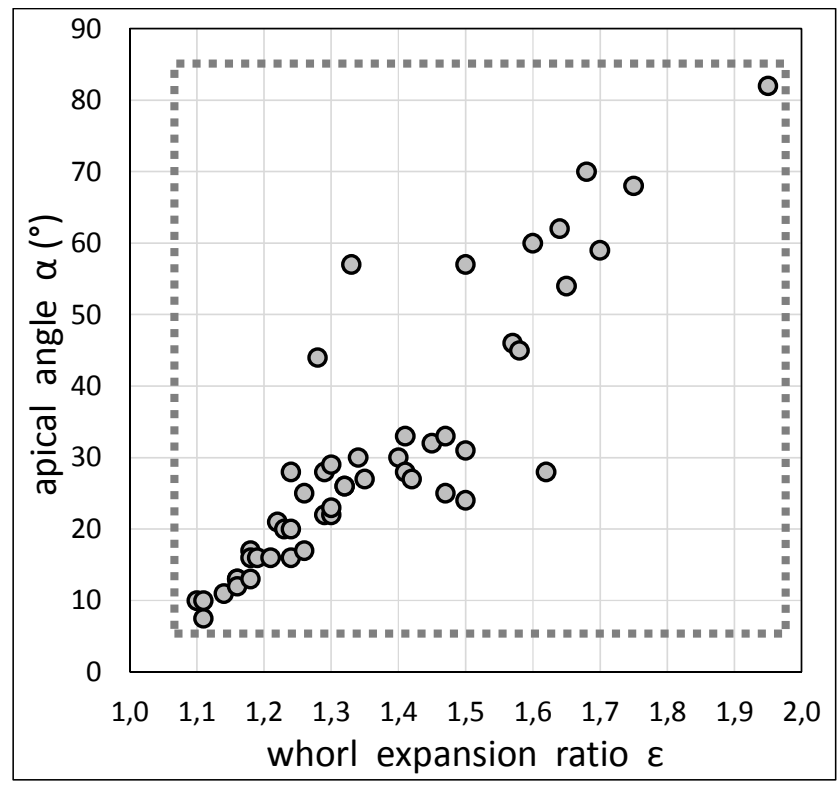

Fig. 5. The recorded distribution of the apical angle $\alpha$ versus the whorl expansion ratio $\varepsilon$ for a set of 51 species of marine gastropods. The apical angle $\alpha$ is strongly increasing with growing values of the expansion ratio $\varepsilon$ (linear regression $r=+0.88, p<0.0001$ ). Due to this strong positive covariance, only about $30 \%$ of the potential morphospace $\{\varepsilon, \alpha\}$ (dotted rectangle: [ $\varepsilon=1.05-1.95] \times\left[\alpha=6^{\circ}-82^{\circ}\right]$ ) is actually occupied 


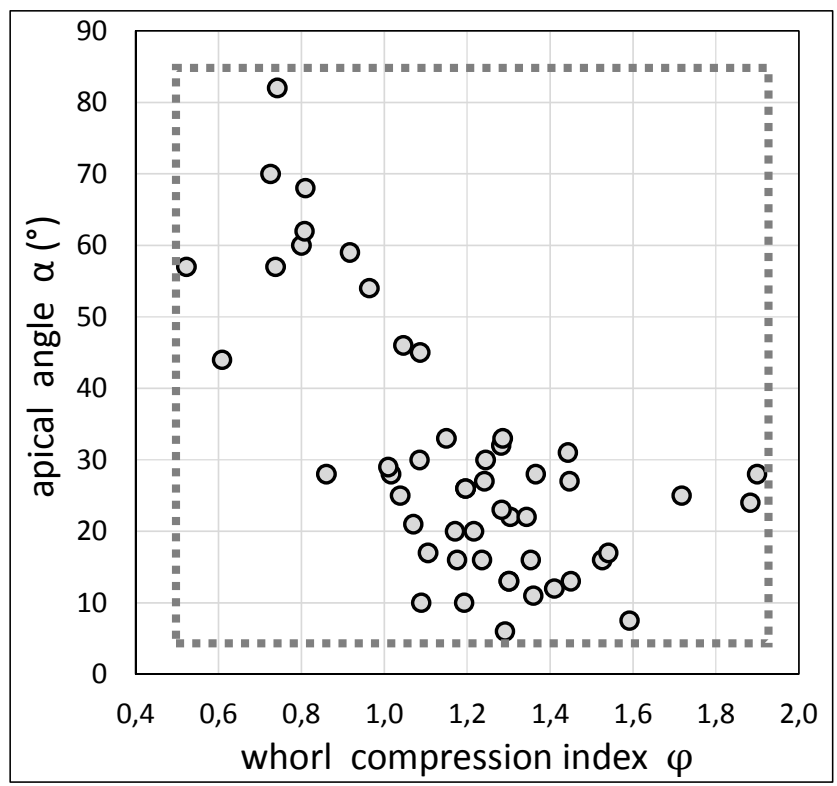

Fig. 6. The recorded distribution of the apical angle $\alpha$ versus the whorl lateral compression index $\varphi$ for a set of 51 species of marine gastropods. The apical angle $\alpha$ decreases with growing values of the whorl compression index $\varphi$ (linear regression $r=-0.68, p<0.0001$ ). Due to this negative covariance, only about $50 \%$ of the potential morphospace $\{\varphi, \alpha\}$ (dotted rectangle: $\left.[\varphi=0.5-1.9] \times\left[\alpha=6^{\circ}-82^{\circ}\right]\right)$ is actually occupied

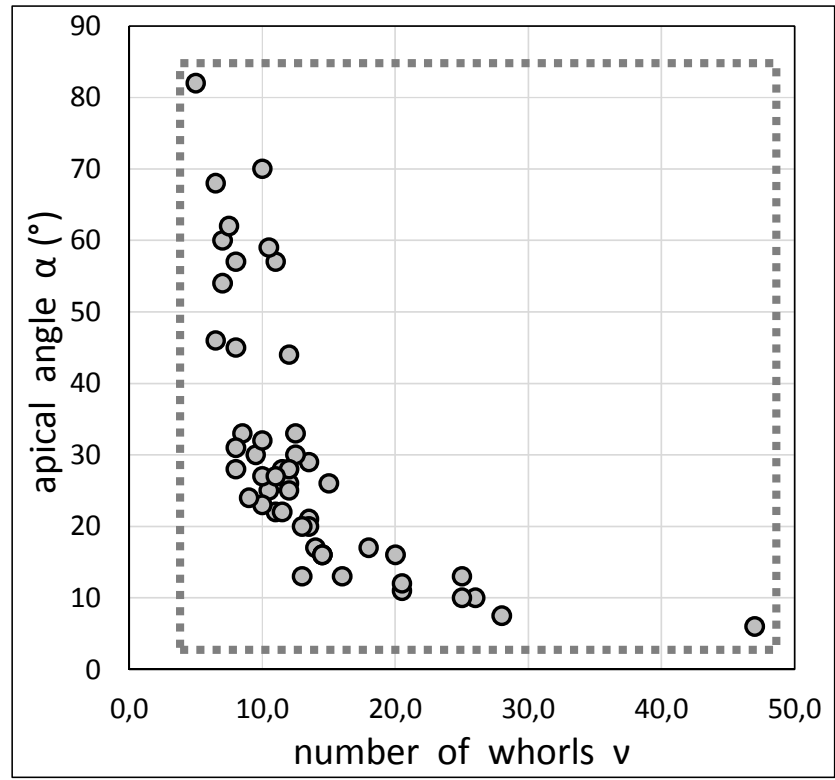

Fig. 7. The recorded distribution of the apical angle $\alpha$ versus the number of whorls $v$ of fully blown shells for a set of 51 species of marine gastropods. The apical angle $\alpha$ is strongly decreasing with growing values of the number of whorls $v$ (power regression $r=-0.87, p<$ 0.0001 ). Due to this strong negative covariance, only about $30 \%$ of the potential morphospace $\{v, \alpha\}$ (dotted rectangle: [ $v=5-48] \times\left[\alpha=6^{\circ}-8^{\circ}\right]$ ) is actually occupied.

Accordingly, the resulting scheme derived here does not provide a complete understanding of the complex regulation process of shell shape. But trying to treat comprehensively both general 
trends and more or less divergent details, already from the very beginning, would likely not help to fully grasp the essential and, thereby, would arguably miss my pragmatic pedagogic objective. Of course, this does not preclude, and would even encourage, going further by subsequently analyzing and discussing those particular points that would not match sufficiently well with some of the general tendencies highlighted above.

\subsection{The Pattern of Four Covariances and Two Mutual Independences that Occur among the Four Parameters $\varepsilon$, $\varphi, v, \alpha$, Describing the Shell-shape in Conispirally Coiled Gastropods}

A priori, no geometrical constrain actually limits the mutual variations of $\varepsilon, v$ and $\varphi$, which, thus, are expected to show mutually independent interspecific variations in this respect. This is fairly well confirmed a posteriori, considering the recorded co-distributions of $\varepsilon$ versus $\varphi$ and of $v$ versus $\varphi$, plotted at Figs. 2 and 3 .

On the contrary, a strong negative interspecific covariance is recorded between the whorl expansion ratio $\varepsilon$ and the number of whorls $v$ of fully blown shells (Fig. 4) which, being admittedly unrelated to any geometrical constraint, must result from another - likely biological - cause. This point will be discussed later.

Now, by contrast, the conispiral coiling process obviously impose intangible geometrical constraints upon the apical angle $\alpha$, making it entirely dependent upon the three other parameters $\varepsilon, v$ and $\varphi$. Accordingly, the value of $\alpha$ is ruled by an equation univocally defining $\alpha$ in terms of $\varepsilon, v$ and $\varphi$, as demonstrated in Appendix 2:

$$
\begin{aligned}
& \alpha=2 . \operatorname{arctg}\left\{(1 / \varphi) \cdot\left(1-1 / \varepsilon^{v-1}\right) /\left[\left(\varepsilon-1 / \varepsilon^{v-1}\right) /(\varepsilon-\right.\right. \\
& \left.\left.1)-1 / 2-\left(1 / \varepsilon^{v-1}\right) / 2\right]\right\}
\end{aligned}
$$

In practice (Fig. 4), $1 / \varepsilon^{\mathrm{v}-1}$ obviously remains substantially less than 1 , so that the contribution of this term is comparatively weak. Neglecting it in equation (1) highlights the major direct dependence of the apical angle $\alpha$ upon $\varphi$ and $\varepsilon$ :

$$
\alpha \approx 2 . \operatorname{arctg}\{(2 / \varphi) \cdot(\varepsilon-1) /(\varepsilon+1)\}
$$

Accordingly, the partial derivatives $\partial \alpha / \partial \varepsilon$ and $\partial \alpha / \partial \varphi$ are respectively positive and negative while $\partial \alpha / \partial v$ is $\approx 0$ (see Appendix 2). Yet, the weak, practically negligible direct dependence of $\alpha$ upon $v$ does not preclude a strong, indirect dependence of $\alpha$ upon $v$, as shown later.

Full derivation of equation (1) with respect to the three other parameters unveils the origin of each of the three corresponding covariances $\alpha-\varepsilon, \alpha-\varphi$, $\alpha-v$, recorded at Figs. 5 to 7 . According to equation (1):

* the dependence of $\alpha$ upon $\varepsilon$ is ruled by the following differential equation:

$$
\underset{(\partial \alpha / \partial \varepsilon]^{\prime}=(\partial \varphi / \partial \varepsilon)}{=}(\partial \alpha / \partial v)(\partial v / \partial \varepsilon)+(\partial \alpha / \partial \varepsilon)+
$$

with, as mentioned above, $\partial \alpha / \partial v \approx 0$. Also, $(\partial \varphi / \partial \varepsilon) \approx 0$ due to the independence between $\varepsilon$ and $\varphi$ (Fig. 2). Thus, finally, $[\mathrm{d} \alpha / \mathrm{d} \varepsilon] \approx(\partial \alpha / \partial \varepsilon)$ and, as $\partial \alpha / \partial \varepsilon$ is positive (see above), this explains, accordingly, the positive covariance recorded between $\alpha$ and $\varepsilon$ (Fig. 5).

* the dependence of $\alpha$ upon $\varphi$ is ruled by the following differential equation:

$$
\underset{(\partial \alpha / \partial \varphi)}{[d \alpha / d \varphi]}=(\partial \alpha / \partial v)(\partial v / \partial \varphi)+(\partial \alpha / \partial \varepsilon)(\partial \varepsilon / \partial \varphi)+
$$

with, as mentioned above, $\partial \alpha / \partial v \approx 0$. Also, $(\partial \varepsilon / \partial \varphi) \approx 0$ and $\partial v / \partial \varphi \approx 0$, due to the independence of both $\varepsilon$ and $v$ with respect to $\varphi$ (Figs. 2 and 3 ). Thus, finally, $[d \alpha / d \varphi] \approx(\partial \alpha / \partial \varphi)$ and, as $\partial \alpha / \partial \varphi$ is negative (see above), this explains, accordingly, the negative covariance recorded between $\alpha$ and $\varphi$ (Fig. 6).

* the dependence of $\alpha$ upon $v$ is ruled by the following differential equation:

$$
\underset{(\partial \alpha / \partial \varphi)(\partial \varphi / \partial v)}{[d \alpha / d v] \underset{(\partial \alpha / \partial v)}{=}(\partial \alpha / \partial \varepsilon)(\partial \varepsilon / \partial v)+}+
$$

with $\partial \alpha / \partial v \approx 0$ and also $\partial \varphi / \partial v \approx 0$ due to the quasi-independence between $\varphi$ and $v$ (Fig. 3). Thus, finally, $[d \alpha / d v] \approx(\partial \alpha / \partial \varepsilon)(\partial \varepsilon / \partial v)$. As $(\partial \alpha / \partial \varepsilon)$ is positive (see above) and as $(\partial \varepsilon / \partial v)$ is negative, due to the negative covariance between $\varepsilon$ and $v$ (Fig. 4), it follows that $d \alpha / d v$ is negative, thereby explaining the negative covariance recorded between $\alpha$ and $v$ (Fig. 7). Thus, although $\alpha$ as a negligible direct dependence upon $v(\partial \alpha / \partial v \approx 0)$, it has, yet, a strong, indirect dependence upon $v$. This negative indirect dependence of $\alpha$ upon $v$ proceeds from (i) the negative covariance of $\varepsilon$ with $v$ articulated to (ii) the positive covariance of $\alpha$ with $\varepsilon$. 
Thus, while the covariances of $\alpha$ upon $\varepsilon$ and $\alpha$ upon $\varphi$ both result from geometrical constraints only (through $\partial \alpha / \partial \varepsilon$ and $\partial \alpha / \partial \varphi$ respectively), the dependence of $\alpha$ upon $v$ has a mixed origin, involving both geometrical constraints (through $\partial \alpha / \partial \varepsilon)$ and non-geometrical, arguably biological constraints (through $(\partial \varepsilon / \partial v)$ ).

\subsection{Possible Origins of the Strong Negative Covariance between the Number of Whorls $v$ and the Whorl Expansion Ratio \&}

The recorded distribution of $v$ versus $\varepsilon$ (Fig. 4) may be empirically related to (result from) the invariance of the ratio $\mathrm{H}_{v} / \mathrm{H}_{\mathrm{x}}$ between the fully blown shell height $H_{v}$ and the height $H_{x}$ of the apical part of the shell including the $\mathrm{x}$ first whorl revolutions, as shown at Fig. 8. The general expression of the relationship linking $\vee$ to $\varepsilon$, for iso-values of the ratio $H_{v} / H_{x}$, is derived in Appendix 3. The best correlation (minimum standard deviation with recorded data) is obtained with $x=1$, that is with the ratio $H_{v} / H_{1}$. Yet, hardly less good correlations are obtained with $x>1$, as exemplified with $\mathrm{H}_{\mathrm{v}} / \mathrm{H}_{2}$ or $\mathrm{H}_{\mathrm{v}} / \mathrm{H}_{3}$ (Fig. 8).

In the ideal conispiral coiling model, $\mathrm{H}_{\mathrm{v}} / \mathrm{H}_{1}$ is representative of the ratio between the final body-size and the initial body-size (at the protoconch stage). According to the recorded distribution of $v$ versus $\varepsilon$, this ratio has an average value of 112 , to be compared to the range of variation of this ratio in most marine animals: from 5 (Cephalopods, Cetaceans) to 1000 (some Teleosteans), as reported by Andersen et al. [12]. According to this point of view, the strong negative covariance recorded among conispirally coiled marine gastropods between the number of whorl of fully blown shells and the whorl expansion ratio would stem from a trend for invariance of the adult to offspring bodysize ratio (average value: 112 , range: $30-400$ ), Fig. 9. A developmental constraint is thereby tentatively proposed.

Yet, a functional origin for this negative covariance between $v$ and $\varepsilon$ may be also advocated, indeed complementary to the developmental option. The apical part of conispirally coiled shells, including the few first whorls, is a comparatively weakly resistant area [3]. The mechanical solicitations of either biotic or abiotic origins, to which the apical part of the shell is exposed are arguably increasing with the size and weight of the main shell part relative to the apical part (respectively through increased lever effect and through increased inertial contribution of the main shell part).

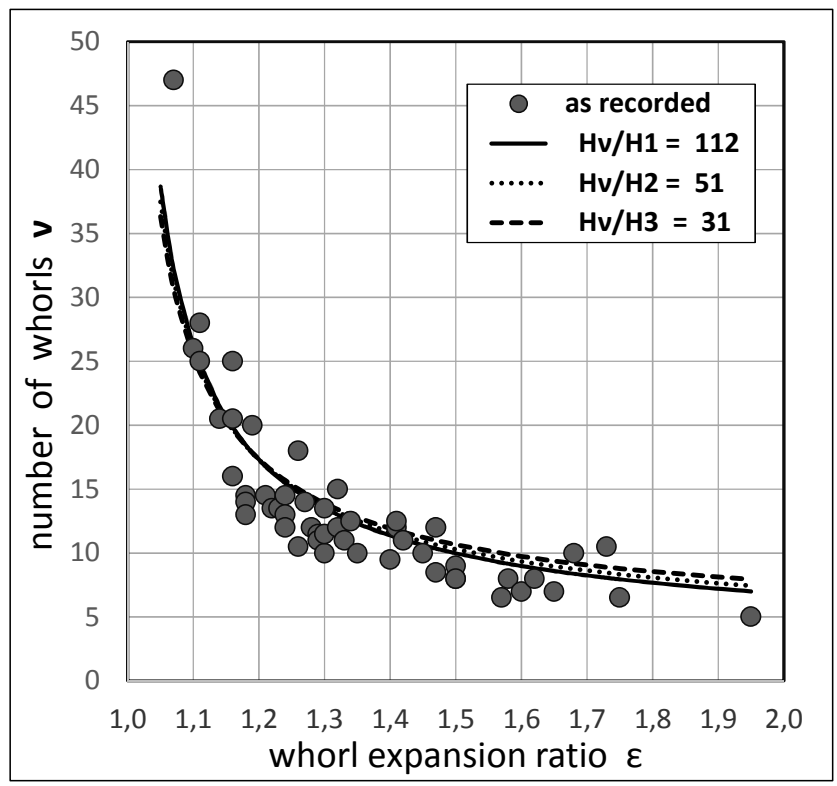

Fig. 8. Distribution of the number of whorls $v$ of fully blown shells versus the whorl expansion ratio $\varepsilon$. The strong negative covariance between $v$ and $\varepsilon$ may possibly result from the approximate invariance of the ratios $\mathrm{Hv} / \mathrm{Hx}$ between the fully blown spire height $\mathrm{Hv}$ and the height $\mathrm{Hx}$ of the apical part of the spire defined as made of the $\mathrm{x}$ first whorls 


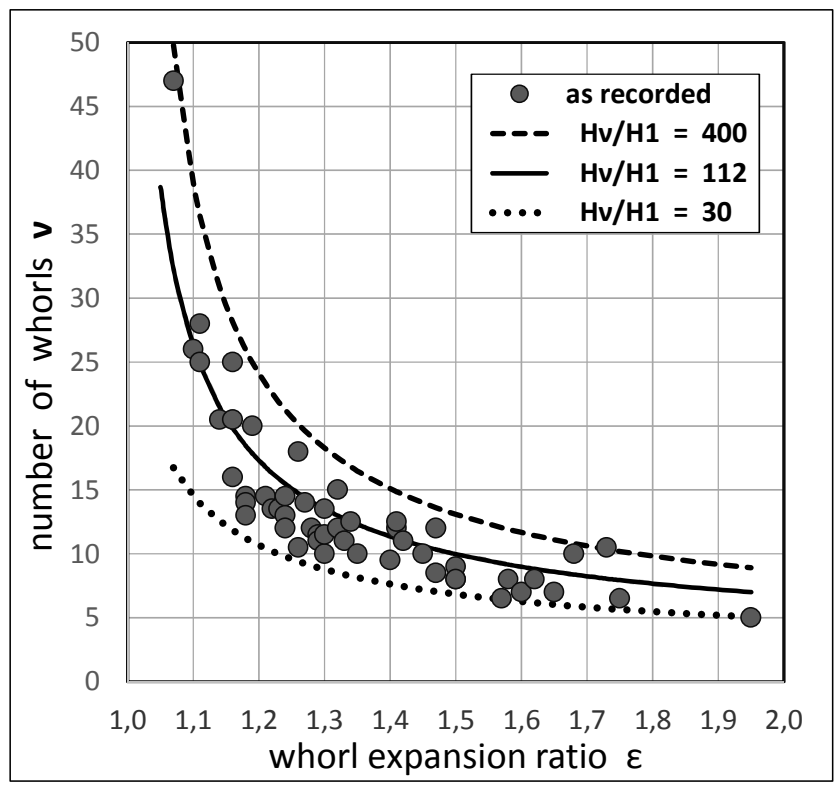

Fig. 9. Iso-values of final to initial body-size ratio compared to the recorded distribution of the number of whorls $v$ versus the whorl expansion ratio $\varepsilon$. The final to initial body-size ratio is identified to the ratio $\mathrm{Hv} / \mathrm{H} 1$ between the total spire height $\mathrm{Hv}$ and the height $\mathrm{H} 1$ of the first whorl, according to the ideal conispiral coiling model

In this perspective, a threshold maximum ratio for the ratio $\mathrm{H}_{\mathrm{v}} / \mathrm{H}_{\mathrm{x}}$ may be conceived, which would discourage further shell growth beyond the number of whorls corresponding to this threshold maximum ratio. For $\mathrm{X}=2$, the computed threshold value of $\mathrm{H}_{\mathrm{v}} / \mathrm{H}_{2}$ would be 51 , range $13-$ 200. For $x=3$, the computed threshold value of $\mathrm{H}_{\mathrm{v}} / \mathrm{H}_{3}$ would be 31 , range $8-120$.

Finally, distinguishing between both possible causes - developmental or functional - of the strong negative invariance between $v$ and $\varepsilon$ remains far from being straightforward, as underlined by Maynard-Smith [8]. As the two hypothesis, here, are complementary, I cautiously propose to retain both of them together.

\subsection{The Restriction of Occupancy of the Potential Morphospace Due to the Four Covariances}

The recorded pairwise covariations among the selected geometrical parameters $\alpha, \varepsilon, v, \varphi$ strongly reduce the actual occupancy of the "potential" morphospace (i.e. the morphospace that would be occupied if there was no covariance). Based on Figs. 4 to 7 , the proportions of potential morphospace occupancy were crudely estimate as: $20 \%$ for $\{v-\varepsilon\} ; 30 \%$ for $\{\alpha-\varepsilon\} ; 50 \%$ for $\{\alpha-\varphi\} ; 30 \%$ for $\{\alpha-v\}$. That means a ratio of occupancy of the "potential" morphospace $[\varphi, \varepsilon, v, \alpha]$ less than $5 \%$ ! Thus, conispiral coiling quite severely constrains the possibility of free combined variations between the four parameters (constraint to which only the combinations $\{\varphi-\varepsilon\}$ and $\{\varphi-v\}$ almost totally escape), thereby reducing the morphospace occupancy by more than a factor 20 !

\subsection{Constraints that Arguably Limit the Range of Variation of the Independent Geometrical Parameters $\varepsilon$ and $\varphi$}

In addition to the restriction of occupancy of the "potential" morphospace, the extension of the "potential" morphospace itself is limited by the ranges of possible variations of $\varphi$ and of $\varepsilon$.

Thus, the whorl expansion rate $\varepsilon$ :
hardly exceeds 2 ; higher values of $\varepsilon$ would imply so low values of the number of whorls $v$ (due to the negative covariance $\mathrm{v}$ - $\varepsilon$, Fig. 4) that the clear conispiral arrangement would progressively vanishes (for examples in Bullidae, Capulidae, Calyptraeidae,...); 
- hardly decreases below 1.05 , since values of $\varepsilon$ less than 1.05 would imply apical angle $\alpha$ less than $5^{\circ}$ (due to the positive covariance $\alpha-\varepsilon$, Fig. 5); such acute apical angle would make the shell, and especially its apex, becoming excessively fragile.

Similarly, the whorl lateral compression ratio $\varphi$,

- hardly decreases below $\approx 0.5$, arguably in order to limit the cantilever of the peristome and also the edge angularity of the peristome, both being causes of mechanical fragility ;

- hardly exceeds 2, for the same reasons.

Moreover, within this range of variation of $\varphi$, there is a trend (with exceptions) for Archeogastropods having $\varphi$ values below 1 and for Meso- and Neo-gastropods often having $\varphi$ values equal or larger than 1.

Also, too low combined values of $\varphi$ and $\varepsilon$ (say, when $\varphi+3(\varepsilon-1)<1.2)$ would require excessive shell wall-surface at given shell volume.

In this study, I deliberately focus upon conispirally coiled shells - appearing explicitly as such when observed externally - that is with no or weak whorl overlap (the very reason why the parameter "translation" of Raup was not involved in the study).

Now, substantially increasing whorl overlap (and thus clearly leaving aside the conispiral coiling pattern), offers a major opportunity to break through the upper limitation $\varphi<2$.

Increasing whorl overlap obviously protect mechanically the series of preceding whorls, thus authorizing to reduce more or less drastically the thickness of their wall, which became internally protected. In turn, the partial dissolution of the internal walls provide mineral materials to strongly thicken the external wall of the last (and outer) whorl and, thereby, drastically increases the mechanical resistance of the external wall. Accordingly, the limitation of $\varphi$ under the threshold value $\approx 2$ (to prevent excessive cantilever of the peristome) is no longer required thanks to the strong thickening of the last whorl. Accordingly, the whorl compression ratio $\varphi$ may now reach values as high as $\approx 10$. This is especially exemplified by some highly evolved groups such as Cones, Cowries and the like. But, in fact, the trend for increasing overlap has begun much earlier and already started in some Archeogastropoda (for example, Neritidae) or some Mesogastropoda (for example, Naticidae, Cassidae, Strombidae).

By this process of (i) enveloping almost all the spire (or even the totality) by the strongly thickened wall of the last whorl, compensated by (ii) dissolution-thinning of the internal original spiral coiling until almost disappearance [13], a kind of box-like mineral exoskeleton, is created. This "exoskeleton fortress" (as qualified by Vermeij [3]) is somewhat functionally homologous to the chitinous exoskeleton of arthropods. Yet, the arthropods are compelled to undergo successive molts, abandoning their previous carapace for a new one, more widely sized - a transitionally dangerous and dispendious procedure. By contrast, the process of those "evolved" gastropods, involving a continuous enlargement of the last whorl at the expense of the partially dissolved internal spire, spares no matter at all and never expose the soft body to any external aggression, even transitorily. In these respects, evolved gastropods undoubtedly outcompete the traditional, sequential process of arthropods, as already suggested by Vermeij [3]. And this evolution was already started among some Archeogastropods. For example, in the genus Nerita, the thickened overlapping last whorl is associated to the quasi-complete dissolution and subsequent remodeling of the internal spire, as reported by Vermeij [3].

Finally, although quite overlooked in this study, the shell handedness (i.e. coiling chirality) is another strikingly evident shape trait, which, however, might perhaps not be considered a truly geometrical parameter. Whatever it may be, it deserves at least a short mention here. Vermeij [3] convincingly argues that shell coiling chirality can in no way be attributed to any directly associated selective advantage that would act in favour of the overwhelming predominance of right-handedness, in particular regarding marine gastropods. Instead of this, some strong conservative pattern of development, strongly imposing right-handedness, would seem more plausible. Or, alternatively, some hypothetical advantage, only indirectly linked to righthandedness, might have been primitively selected.

At last, it is worth noting that substantial limitations of shell morphospace occupancy in gastropods occur not only at the inter-specific level, as discussed above, but also at the 
Table 1. Pairwise relationships among the four geometrical parameters selected to describe the diversity of conispirally coiled shells shapes in marine gastropods. Their nature - either independence or covariance - their sign and level of statistical significance, the attributed origin of each of these relationships are indicated, as well as the corresponding figures where the recorded data is plotted

\begin{tabular}{lllllll}
\hline Covariances & $\begin{array}{l}\boldsymbol{\varepsilon}-\boldsymbol{\varphi} \\
\text { nb. whorls/ } \\
\text { whorl cmpr. }\end{array}$ & $\begin{array}{l}\mathbf{v}-\boldsymbol{\varphi} \\
\text { exp. rate/ } \\
\text { whorl cmpr. }\end{array}$ & $\begin{array}{l}\mathbf{v}-\boldsymbol{\varepsilon} \\
\text { nb. whorls/ } \\
\text { exp. rate }\end{array}$ & $\begin{array}{l}\boldsymbol{\alpha}-\boldsymbol{\varepsilon} \\
\text { apical angle/ } \\
\text { exp. rate }\end{array}$ & $\begin{array}{l}\boldsymbol{\alpha}-\boldsymbol{\varphi} \\
\text { apical angle/ } \\
\text { whorl cmpr. }\end{array}$ & $\begin{array}{l}\boldsymbol{\alpha}-\mathbf{v} \\
\text { apical angle / } \\
\text { nb. whorls }\end{array}$ \\
\hline $\begin{array}{l}\text { Sign \& } \\
\text { significance }\end{array}$ & $\approx \mathbf{0}$ & $\approx \mathbf{0}$ & $\begin{array}{l}\text { strongly } \\
\text { negative }\end{array}$ & $\begin{array}{l}\text { strongly } \\
\text { positive }\end{array}$ & $\begin{array}{l}\text { fairly } \\
\text { negative }\end{array}$ & $\begin{array}{l}\text { strongly } \\
\text { negative }\end{array}$ \\
origin & $r^{2}=0.09$ & $r^{2}=0.06$ & $\begin{array}{l}r=-0.84 \\
r=+0.88\end{array}$ & $\begin{array}{l}r=-0.68 \\
r=-0.87\end{array}$ \\
& no geometric & no geometric & developm. \&/ & geometric & geometric & geometric + \\
& nor biologic & nor biologic & or functional & constraints & constraints & biologic \\
$\mathbf{n}^{\circ}$ figure & constraints & constraints & constraints & & & constraints \\
\hline
\end{tabular}

intra-specific level [14-16]. Moreover, once again, a negative covariance is instrumental, applying to inter-individual variations of the whorl size and the number of whorl of fully blown shells $[15,16]$.

\section{CONCLUSION}

Conispirally coiled shells lend themselves particularly well to the analysis of the intricate interplay between the four geometrical parameters $\alpha, \varepsilon, v, \varphi$, selected to describe the plentiful diversity of their shapes. Among the six pairwise combinations of these four parameters, four strong covariances are highlighted, which severely reduce the occupancy of the "potential" morphospace, by a factor in excess of twenty! And, thereby, these four covariances delineate the complex contours of the actually occupied 4d morphospace. The sign, significance and attributed origins of these covariances are summarized in Table 1.

Thus, in spite of the profusion of shell-shape diversity observed among conispirally coiled gastropods shells, strong constraints applying to the free mutual variations of the four descriptive parameters of shell shape $\{\alpha, \varepsilon, v, \varphi\}$ actually lead to discard about $95 \%$ of the full potential range of variations of shell shapes that, otherwise, would have been open to occupancy.

Admittedly, the decisive role of geometrical constraints, causing the severe limitations of morphospace occupancy in conispirally coiled gastropods shells, is not new and goes back, at least, to d'Arcy Thompson.

Yet, adding to conventional approaches the consideration of the number of whorls of fully blown shell $v$ (a too often overlooked parameter) and also the degree of whorl compression $\varphi$, has permit a renewed mathematical analysis of the factors that delineate, in details, the actual range of morphospace occupancy.

Moreover, if geometrical incompatibilities make the bulk of these constraints (as might have been expected), a likely biological constraint (either developmental or functional) is also highlighted, resulting in the strong negative covariance recorded between the number of whorls $v$ and the whorl expansion ratio $\varepsilon$. A point which had, so far, apparently escaped any detailed analysis.

\section{ACKNOWLEDGEMENTS}

The constructive comments of three reviewers are sincerely acknowledged. Thanks also to Jean-Louis Dommergues and Emmanuel Fara for fruitful discussion on the subject.

\section{COMPETING INTERESTS}

Author has declared that no competing interests exist.

\section{REFERENCES}

1. Thompson d'Arcy W. On growth and form. Cambridge University Press; 1917.

2. Raup DM. The geometry of coiling in gastropods. Proceedings of the National Academy of Science USA. 1961;47:602609.

3. Vermeij GJ. A natural history of shells. Princeton University Press, Princeton USA; 1993.

4. Raup DM, Michelson A. Theoretical morphology of the coiled shell. Science. 1965;147(3663):1294-1295.

5. Cotton PA, Rundle SD, Smith KE. Trait compensation in marine gastropods: 
Shell shape, avoidance behaviour and susceptibility to predation. Ecology. 2004; 85(6):1581-1584.

6. Schindel DE. Unoccupied morphospace and the coiled geometry of gastropods: Architectural constraint or geometric covariation, in causes of Evolution. Ross RA, Allmon WD, Eds. University of Chicago Press, Chicago III, USA. 1990; 270-304.

7. Erwin DH. Disparity: Morphological pattern and developmental context. Paleontology. 2007;50(1):57-73.

8. Maynard-Smith J, Burian R, Kauffman S, Alberch P, Campbell J, Goodwin B, Lande R, Raup D, Wolpert L. Developmental constraints and evolution: A perspective from the Mountain Lake Conference on development and evolution. Quarterly Review of Biology. 1975;60(3): 265-287.

9. Raup DM. Geometric analysis of shell coiling: General problems. Journal of Paleontology. 1966;40(5):1178-1190.

10. Robin A. Encyclopedia of marine gastropods. ConchBooks, Hackenheim, Germany; 2008.

11. Hill Coquillages L. Konemann eds, Köln, Germany; 1997.
12. Andersen $\mathrm{KH}$, Berge $\mathrm{T}$, Gonçalves RJ, et al. Characteristic sizes of life in the oceans, from bacteria to whales. Annual Review of Marine Science. 2016;8:3.13.25.

DOI:10.1146/annurev-marine-122414034144

13. Kohn AJ, Myers ER, Meenakshi VR. Interior remodeling of the shell by a gastropod mollusc. Proceedings of the National Academy of Sciences. 1979; 76(7):3406-3410.

14. Gould SJ. A developmental constraint in cerion, with comments on the definition and interpretation of constraint in evolution. Evolution. 1989;43(3):516539.

15. Béguinot J. Régulation du développement dimensionnel de la coquille chez trois espèces de gasteropodes. Bulletin Société Linnéenne de Lyon. 2014;83(5-6):119126.

16. Béguinot J. Stabilisation de la taille de coquille adulte en dépit de la variabilité de la croissance, chez un gastéropode marin, la Natice commune, Euspira catena. Bulletin Société Linnéenne de Bordeaux. 2014;42(2):239-248. 


\section{APPENDIX 1}

\section{List of the 51 species involved in the study}

Including the whorl expansion ratio ' $\varepsilon$ ', the number of whorls of fully blown shell ' $v$ ', the apical angle ' $\alpha$ ' $\left({ }^{\circ}\right)$ and the whorl lateral compression index ' $\varphi$ ', for each of the 51 studied species.

As mentioned in section Methods, the values of the four parameters are obtained from one unique fully blown shell for each species under consideration. Accordingly this means that intra-specific variability of shell parameters is not accounted for, which is coherent with the aim of the study which addresses specifically inter-specific variations across a large taxonomic range, encompassing a large portion of shell shape variations among marine gastropods.

\begin{tabular}{|c|c|c|c|c|c|c|c|c|c|}
\hline & $\varepsilon$ & $\mathbf{v}$ & $\alpha$ & $\varphi$ & & $\varepsilon$ & $\mathbf{v}$ & $\alpha$ & $\varphi$ \\
\hline Amaea ferminiana (Dall 1908) & 1.30 & 13.5 & 29 & 1.01 & Fusivoluta barnardi Rehd.1969 & 1.62 & 8.0 & 28 & 1.90 \\
\hline Amaea mitchelli (Dall 1889) & 1.32 & 15.0 & 26 & 1.20 & Fusivoluta clarkei Rehder 1969 & 1.50 & 9.0 & 24 & 1.88 \\
\hline Amaea teramachii Kuroda 1955 & 1.22 & 13.5 & 21 & 1.07 & $\begin{array}{l}\text { Gazameda gonostoma Valenc. } \\
1832\end{array}$ & 1.16 & 16.0 & 13 & 1.30 \\
\hline $\begin{array}{l}\text { Archimediella carinifera (Lmk } \\
\text { 1822) }\end{array}$ & 1.29 & 11.0 & 22 & 1.30 & Littoraria coccinea (Gmelin 1791) & 1.65 & 7.0 & 54 & 0.96 \\
\hline Astraea undosa (Wood 1828) & 1.64 & 7.5 & 62 & 0.81 & $\begin{array}{l}\text { Maoricolpus roseus (Quoy \& G. } \\
\text { 1834) }\end{array}$ & 1.23 & 13.5 & 20 & 1.17 \\
\hline $\begin{array}{l}\text { Calliostoma annulatum } \\
\text { (Light.1786) }\end{array}$ & 1.5 & 8.0 & 57 & 0.74 & Mesalia brevialis (Lamarck 1822) & 1.24 & 13.0 & 20 & 1.22 \\
\hline $\begin{array}{l}\text { Calliostoma ligatum (Gould } \\
1849 \text { ) }\end{array}$ & 1.75 & 6.5 & 68 & 0.81 & $\begin{array}{l}\text { Pleuroploca wattersae Kilburn } \\
1974\end{array}$ & 1.50 & 8,0 & 31 & 1.44 \\
\hline $\begin{array}{l}\text { Calliotectum smithi (Bartsch } \\
\text { 1942) }\end{array}$ & 1.47 & 12.0 & 25 & 1.72 & $\begin{array}{l}\text { Rhynocoryne humboldti (Val. } \\
\text { 1832) }\end{array}$ & 1.32 & 12.0 & 26 & 1.20 \\
\hline $\begin{array}{l}\text { Calliotectum tibiaeforme } \\
\text { (Kur.1931) }\end{array}$ & 1.42 & 11.0 & 27 & 1.45 & Tectus conus (Gmelin 1791) & 1.70 & 10.5 & 59 & 0.92 \\
\hline $\begin{array}{l}\text { Cancellaria uniangulata Desh. } \\
1830\end{array}$ & 1.57 & 6.5 & 46 & 1.05 & Tectus pyramis (von Born 1778) & 1.33 & 11.0 & 57 & 0.52 \\
\hline $\begin{array}{l}\text { Cerithidea largillierti (Philippi } \\
\text { 1849) }\end{array}$ & 1.41 & 12.5 & 33 & 1.15 & Tectus triserialis (Lamarck 1822) & 1.28 & 12.0 & 44 & 0.61 \\
\hline $\begin{array}{l}\text { Cerithidea pulchra (Adams } \\
1852 \text { ) }\end{array}$ & 1.34 & 12.5 & 30 & 1.09 & Terebra guttata (Röding 1798) & 1.16 & 20.5 & 12 & 1.41 \\
\hline $\begin{array}{l}\text { Cerithium alexandri (Tomlin } \\
\text { 1923) }\end{array}$ & 1.30 & 11.5 & 22 & 1.34 & Terebra larvaeformis Hinds 1844 & 1.18 & 14.5 & 16 & 1.18 \\
\hline $\begin{array}{l}\text { Cerithium columna Sowerby } \\
1834\end{array}$ & 1.40 & 9.5 & 30 & 1.24 & $\begin{array}{l}\text { Terebra subulata (Linnaeus } \\
\text { 1767) }\end{array}$ & 1.14 & 20.5 & 11 & 1.36 \\
\hline $\begin{array}{l}\text { Cerithium munitum Sowerby } \\
1855\end{array}$ & 1.26 & 10.5 & 25 & 1.04 & $\begin{array}{l}\text { Terebralia palustris (Linnaeus } \\
\text { 1767) }\end{array}$ & 1.24 & 12.0 & 28 & 0.86 \\
\hline $\begin{array}{l}\text { Cerithium novaehollandae } \\
\text { Ad.1855 }\end{array}$ & 1.29 & 11.5 & 28 & 1.02 & $\begin{array}{l}\text { Terebralia semistriata (Mörch } \\
\text { 1852) }\end{array}$ & 1.35 & 10.0 & 27 & 1.24 \\
\hline Chicoreus ramosus (L. 1758) & 1.95 & 5.0 & 82 & 0.74 & $\begin{array}{l}\text { Terebralia sulcata (von Born } \\
\text { 1778) }\end{array}$ & 1.45 & 10.0 & 32 & 1.28 \\
\hline $\begin{array}{l}\text { Cinguloterebra commaculata } \\
\text { (Gm.) }\end{array}$ & 1.11 & 28.0 & 7.5 & 1.59 & Thatcheria mirabilis Angas 1877 & 1.68 & 10.0 & 70 & 0.73 \\
\hline $\begin{array}{l}\text { Cinguloterebra connelli } \\
\text { (B.\&C.1985) }\end{array}$ & 1.10 & 26.0 & 10 & 1.09 & Tibia fusus (Linnaeus 1758) & 1.26 & 18.0 & 17 & 1.54 \\
\hline $\begin{array}{l}\text { Cinguloterebra pretiosa (Re. } \\
\text { 1842) }\end{array}$ & 1.11 & 25.0 & 10 & 1.19 & $\begin{array}{l}\text { Trigonostoma scalare (Gmelin } \\
\text { 1791) }\end{array}$ & 1.60 & 7.0 & 60 & 0.80 \\
\hline $\begin{array}{l}\text { Cinguloterebra triseriata } \\
\text { (Gray1834) }\end{array}$ & 1.07 & 47.0 & 6 & 1.29 & Turitella exoleta (Linnaeus 1758) & 1.21 & 14.5 & 16 & 1.35 \\
\hline Duplicaria duplicata (L. 1758) & 1.24 & 14.5 & 16 & 1.53 & Turitella ligar Deshayes 1843 & 1.19 & 20.0 & 16 & 1.24 \\
\hline $\begin{array}{l}\text { Epitomium rupicola (Kurtz } \\
\text { 1860) }\end{array}$ & 1.47 & 8.5 & 33 & 1.29 & $\begin{array}{l}\text { Turitella monterosatoi Kobelt } \\
1887\end{array}$ & 1.18 & 14.0 & 17 & 1.11 \\
\hline Epitomium scalare (L. 1758) & 1.58 & 8.0 & 45 & 1.09 & Turitella terebra (Linnaeus 1758) & 1.16 & 25.0 & 13 & 1.30 \\
\hline $\begin{array}{l}\text { Epitomium tenebrosum } \\
\text { Sow.1903 }\end{array}$ & 1.30 & 10.0 & 23 & 1.28 & $\begin{array}{l}\text { Turitella ungulina (Linnaeus } \\
\text { 1758) }\end{array}$ & 1.18 & 13.0 & 13 & 1.45 \\
\hline $\begin{array}{l}\text { Fusinus caparti (Ad.\& Knuts. } \\
\text { 1955) }\end{array}$ & 1.41 & 12.0 & 28 & 1.37 & & & & & \\
\hline
\end{tabular}




\section{APPENDIX 2}

Mathematical derivation of the geometrically constrained pairwise covariances among the four parameters $\varepsilon, \varphi, v, \alpha$, which describe the main shell-shape traits in ideally conispirally coiled gastropods

Derivations below apply to the context of an ideally conispirally coiled shell but, for the essential, may be extended to the innumerable real shells approaching the ideal model.

As shown at Fig. 1, the height of the $x^{\text {th }}$ whorl (measured parallel to coiling axis) is:

$$
h_{x}=h_{1} \cdot \varepsilon^{x-1}
$$

with $\mathrm{h}_{1}$ as the height of the first whorl in the ideal conispiral model.

Similarly, the width $w_{x}$ of the $x^{\text {th }}$ whorl (measured perpendicular to coiling axis) is:

$$
\mathrm{w}_{\mathrm{x}}=\mathrm{w}_{1} \cdot \varepsilon^{\mathrm{x}-1}
$$

with $\mathrm{w}_{1}$ as the width of the first whorl in the ideal conispiral model.

The whorl compression index $\varphi$, as defined above, is thus:

$$
\varphi=h_{x} / w_{x}=h_{1} / w_{1}
$$

Accordingly, the spire height (measured parallel to coiling axis) after $x$ turns, $H_{x}$, is:

$$
H_{x}=h_{1} \cdot\left(\varepsilon^{x}-1\right) /(\varepsilon-1)
$$

In particular, the fully blown shell height $H_{v}$ is equal to:

$$
H_{v}=h_{1} \cdot\left(\varepsilon^{v}-1\right) /(\varepsilon-1)
$$

Elementary trigonometry derived from Fig. 1 shows that the apical angle $\alpha$ is such that:

$$
\operatorname{tg}(\alpha / 2)=\left(w_{v}-w_{1}\right) /\left(H_{v}-h_{1} / 2-h_{v} / 2\right)
$$

According to equations (A.2), (A.3), (A.5), it comes:

$$
\begin{aligned}
& \operatorname{tg}(\alpha / 2)=\left(w_{1} / h_{1}\right)\left(\varepsilon^{v-1}-1\right) /\left[\left(\varepsilon^{v}-1\right) /(\varepsilon-1)-\varepsilon^{v-1} / 2-1 / 2\right] \\
& \operatorname{tg}(\alpha / 2)=(1 / \varphi) \cdot\left(\varepsilon^{v-1}-1\right) /\left[\left(\varepsilon^{v}-1\right) /(\varepsilon-1)-\varepsilon^{v-1} / 2-1 / 2\right]
\end{aligned}
$$

Accordingly,

$$
\alpha=2 \cdot \operatorname{arctg}\left\{(1 / \varphi) \cdot\left(\varepsilon^{v-1}-1\right) /\left[\left(\varepsilon^{v}-1\right) /(\varepsilon-1)-\varepsilon^{v-1} / 2-1 / 2\right]\right\}
$$

or as well:

$$
\alpha=2 . \operatorname{arctg}\left\{(1 / \varphi) \cdot\left(1-1 / \varepsilon^{v-1}\right) /\left[\left(\varepsilon-1 / \varepsilon^{v-1}\right) /(\varepsilon-1)-1 / 2-\left(1 / \varepsilon^{v-1}\right) / 2\right]\right\}
$$

Thus, the apical angle $\alpha$ is univocally linked to the three other parameters $\varepsilon, v, \varphi$ by inevitable geometrical constraints associated to the ideal conispirally-coiling model.

Yet, in practice, the term $\left(1 / \varepsilon^{v-1}\right)$ is little compared to 1 , so that, in first but sufficient approximation, the expression of the apical angle a may be approximated by: 
Thus:

$(\partial \alpha / \partial \varphi)$ is negative, having the same sign as $(\partial \operatorname{tg}(\alpha / 2) / \partial \varphi) \approx-2(\varepsilon-1) /(\varepsilon+1) / \varphi^{2}$, which is actually confirmed by Fig. 6;

$(\partial \alpha / \partial \varepsilon)$ is positive, having the same sign as $(\partial \operatorname{tg}(\alpha / 2) / \partial \varepsilon) \approx 4 /(\varepsilon+1)^{2} / \varphi$, which is actually confirmed by Fig. 5;

While $(\partial \alpha / \partial v)$ may be comparatively neglected as argued above.

Thus, in practice, the apical angle $\alpha$ is geometrically linked to the whorl expansion ratio $\varepsilon$ and to the whorl compression index $\varphi$ only. In particular, this is the reason why, in conispirally coiled shells, the apical angle rightly appears remaining constant all along the shell development (i.e. shell conicity remains the same, irrespective of the increasing number of whorls during shell development).

Yet, the negligible value of the partial derivative $(\partial \alpha / \partial v)$ does not imply that the apical angle $\alpha$ is independent of the number of whorls $v$ of fully blown shells. On the contrary, as shown at Fig. 7, recorded values of $\alpha$ are strongly decreasing with increasing number of whorls $v$. This results of an indirect dependence of $\alpha$ upon $v$ via $\varepsilon$ : namely, $\alpha$ is positively correlated to $\varepsilon$ due to geometrical constraint (Fig. 5 and equation (A.9)) and, as $\varepsilon$ is negatively correlated to $v$ (Fig. 4) for some biological reason discussed above, it follows that, finally, $\alpha$ and $v$ actually are negatively correlated (Fig. 7). In this particular case, the correlation thus stems from (i) a biological constraint, subsequently relayed by (ii) a geometrical constraint due to conispiral coiling mode.

Let put this in analytic terms of partial derivatives. In all generality:

* Dependence of $\alpha$ upon $v$

$$
[d \alpha / d v]=(\partial \alpha / \partial v)+(\partial \alpha / \partial \varepsilon)(\partial \varepsilon / \partial v)+(\partial \alpha / \partial \varphi)(\partial \varphi / \partial v)
$$

Here, $(\partial \alpha / \partial v)$ is considered comparatively negligible (see above), as is also $(\partial \varphi / \partial v)$ from the expected and actually recorded quasi-independence between $\varphi$ and $v$ (Fig. 3). Accordingly:

$$
[d \alpha / d v] \approx(\partial \alpha / \partial \varepsilon)(\partial \varepsilon / \partial v)
$$

As just mentioned above, the positive partial derivative $(\partial \alpha / \partial \varepsilon)$ and the negative partial derivative $(\partial \varepsilon / \partial v)$ highlight the respective contributions of geometrical and biological constraints resulting in the negative value of [da/dv] and, accordingly, the negative covariance between $\alpha$ and $v$ (Fig. 7).

* Dependence of $\alpha$ upon $\varepsilon$

$$
[d \alpha / d \varepsilon]=(\partial \alpha / \partial v)(\partial v / \partial \varepsilon)+(\partial \alpha / \partial \varepsilon)+(\partial \alpha / \partial \varphi)(\partial \varphi / \partial \varepsilon)
$$

Accounting for the comparatively negligible values of $(\partial \alpha / \partial v)$ (see above) and of $(\partial \varphi / \partial \varepsilon)$, from Fig. 2, it comes:

$$
[\mathrm{d} \alpha / \mathrm{d} \varepsilon] \approx(\partial \alpha / \partial \varepsilon)
$$

Here, the positive covariance $[d \alpha / d \varepsilon]$ between $\alpha$ and $\varepsilon$ (Fig. 5) results entirely from the geometrical constraint (conispiral coiling) implying the positive value of $(\partial \alpha / \partial \varepsilon)$ (equation (A.9)).

\section{${ }^{*}$ Dependence of $\alpha$ upon $\varphi$}

$$
[d \alpha / d \varphi]=(\partial \alpha / \partial v)(\partial v / \partial \varphi)+(\partial \alpha / \partial \varepsilon)(\partial \varepsilon / \partial \varphi)+(\partial \alpha / \partial \varphi)
$$


Accounting for the comparatively negligible values of both $(\partial \alpha / \partial v)$ and $(\partial v / \partial \varphi)$ (see above) and of $(\partial \varepsilon / \partial \varphi)$, as shown by Fig. 2, it comes:

$$
[\mathrm{d} \alpha / \mathrm{d} \varphi] \approx(\partial \alpha / \partial \varphi)
$$

Here, the negative covariance [da/d $\varphi$ ] between $\alpha$ and $\varphi$ (Fig. 6) results entirely from the geometrical constraint (conispiral coiling) implying the negative value of $(\partial \alpha / \partial \varphi)$ (equation (A.9)).

\section{APPENDIX 3}

\section{Derivation of the relation linking $\vee$ to $\varepsilon$ so that the ratio $H_{v} / H_{x}$ remains constant}

In the ideal conispiral approximation, the spire height, $H_{n}$, for a number ' $n$ ' of whorls, is equal to $\left(\varepsilon^{n}\right.$ 1)/( $\varepsilon-1) \cdot h_{1}$ with $h_{1}$ as the height of the first whorl. Accordingly, the ratio $H_{v} / H_{x}$ between the total spire height $H_{v}$ and the height $H_{x}$ of the apical part of the spire including the $x$ first whorls is equal to $\left(\varepsilon^{v}\right.$ 1)/( $\left.\varepsilon^{x}-1\right)$. Thus, $H_{v} / H_{x}$ remaining at a constant given value $\rho$ implies the following dependence of $v$ upon $\varepsilon$ :

$$
\mathrm{V}=\ln \left[\rho \cdot\left(\varepsilon^{\mathrm{x}}-1\right)+1\right] / \ln (\varepsilon)
$$

(c) 2017 Béguinot; This is an Open Access article distributed under the terms of the Creative Commons Attribution License (http://creativecommons.org/licenses/by/4.0), which permits unrestricted use, distribution, and reproduction in any medium, provided the original work is properly cited. 